\title{
INVESTIGATION OF SOUND ABSORPTION PROPERTIES OF BARK CLOTH NONWOVEN FABRIC AND COMPOSITES
}

\author{
Samson Rwawiire ${ }^{1,2^{\star}}$, Blanka Tomkova ${ }^{1}$, Eulalia Gliscinska ${ }^{3}$, Izabella Krucinska ${ }^{3}$, \\ Marina Michalak ${ }^{3}$, Jiri Militky ${ }^{1}$, Abdul Jabbar ${ }^{1}$ \\ ${ }^{1}$ Department of Material Engineering, Faculty of Textile Engineering, Technical University of Liberec, Studentska 4, 46115 Liberec, Czech Republic \\ ${ }^{2}$ Department of Textile and Ginning Engineering, Faculty of Engineering, Busitema University, P.O Box 236, Tororo, Uganda \\ ${ }^{3}$ Department of Material and Commodity Sciences and Textile Metrology, Faculty of Material Technologies and Textile Design, \\ Lodz University of Technology, ul. Zeromskiego 116, 90-924 Lodz, Poland \\ *Corresponding author: rbsjunior@gmail.com
}

\begin{abstract}
:
The quest for sound-absorbing materials that are not only environmentally friendly, but also sustainable is the foremost reason for natural fibre-acoustic materials. Bark cloth is a natural non-woven fabric that is largely produced from Ficus trees. An exploratory investigation of bark cloth a non-woven material and its reinforcement in epoxy polymer composites has been fabricated and investigated for the sound absorption properties so as to find the most suitable applications and also to see whether bark cloth can be used in some applications in place of man-made fibres. Three types of material species were investigated with their respective composites. The fibre morphology showed bark cloth to be a porous fabric that showed promising sound absorption properties at higher frequencies. The sound absorption results of four-layer material selections of Ficus natalensis, Ficus brachypoda and Antiaris toxicaria bark cloth showed sound absorption coefficient of $0.7 ; 0.71$ and $0.91 \mathrm{at} f>6400 \mathrm{~Hz}$, respectively. The bark cloth reinforced laminar epoxy composites had reduced sound absorption coefficients, which ranged from 0.1 to 0.35 , which was attributed to decreased porosity and vibration in the bark cloth fibre network.
\end{abstract}

\section{Keywords:}

Bark cloth, Acoustic properties, Epoxy, Composites

\section{Introduction}

Increased industrialisation and growth of the metropolis world over leads to noise pollution from various sources. According to a new World Health Organization report, traffic-related noise accounts for over one million healthy years of life lost annually to ill health, disability, or early death in western Europe. Among environmental factors contributing to disease in Europe, environmental noise leads to a disease burden that is only second in magnitude to that from air pollution. Noise pollution causes or contributes to not only annoyance and sleep disturbance, but also heart attacks, learning disabilities, and tinnitus [1]. The use of acoustic absorbing materials is the most effective means used in buildings, automotive, aerospace and other transport vehicles. Synthetic materials such as polymer foams, glass fibre, polyester, mineral wool are the leading sound absorption or noise reduction materials used. However, the biggest drawback is that most of the raw materials sources are from fossil fuels. In order to create a new class of materials, sustainable and renewable material sources are being explored as a consequence of the Kyoto protocol on global climate change [2].

The ecological 'green' image of cellulose fibres and considerable mechanical properties fit for secondary structures coupled with low health risk is the leading argument for innovation and development of products, which are biodegradable and can be applied to the automotive industries, building and construction [3-5]. Plant-based fibres like flax, hemp; nettle and kenaf, which were once used to provide textile fibre in the western world, have attracted renewed interest this time for industrial composite applications [6-8].

According to the report [9] on Global Natural Fibre Composites Market 2014-2019: Trends, Forecast and Opportunity Analysis, showed that by 2016 , the natural fibre composites market is expected to be worth US 531.2 million with an expected annual growth rate of $11 \%$ for the next 5 years [10]. Currently, natural fibres account to over $14 \%$ share of reinforcement materials; however, the share is projected to rise to $28 \%$ by 2020 , amounting to about 830,000 tons of natural fibres [11]. This, therefore, shows the importance of study of acoustic properties of natural fibre-reinforced composites since their utilisation, especially in the automotive sector, is on the rise.

Liu et al. [12] utilised wood fibre and rice straw for the development of thermal and acoustic insulation panels with thickness ranging from $50-150 \mathrm{~mm}$. The sound absorption coefficient of the developed biocomposites was above 0.8 for a wide frequency range $250-7000 \mathrm{~Hz}$. The acoustic properties of jute felts and rubber composites were investigated by Fatima and Mohanty [13]. Addition of rubber was found to reduce the noise-reduction coefficient whereas treatment with alkali had no significant change on the sound absorption coefficient. 
Zulkifh et al. [14] studied the acoustic properties of multilayer coir fibres, and found out that the developed panels had a sound absorption coefficient of $0.70-0.80$ in the frequency range of $1000-1800 \mathrm{~Hz}$.

Yang et al. [15] investigated the acoustic properties in the range of $500-8000 \mathrm{~Hz}$ of rice straw-wood particle composite boards and found that the sound absorption coefficient was higher than wood-based materials. Sound-absorbing materials are porous in nature and therefore, the sound absorption coefficient is proportional to their thickness and inversely proportional to the resistance of air through them [16].

Various cellulose fibres have been investigated for acoustic properties such as coir [16-19], sugarcane bagasse [20], tea leaf fibre [21], rice straw, wood particle composite [22], kapok [23]; therefore, cellulose fibres, which are usually discarded, are being explored for value-added products, sound absorption panels inclusive.

According to United Nations Educational, Scientific and Cultural Organization (UNESCO), Bark cloth, a non-woven fabric has been in production in Uganda for over six centuries; however, there's a limited study of the non-woven felt, which is produced through a series of pummelling processes. That notwithstanding, in 2005, UNESCO proclaimed it as a 'Masterpiece of the Oral and Intangible Heritage of Humanity' [24].

Non-woven felts have been investigated as sound absorption materials by various researchers [25-27]. Therefore, in this study, an exploratory investigation of the sound absorption properties of the non-woven fabric from the inner bark of mutuba trees (Ficus natalensis) is characterised. In terms of green credentials and sustainability, the trees grow naturally in Central Uganda and do not need fertilisers. The fabric layers were studied and their performance in sound absorption was evaluated. Epoxy polymer was used as a binder of the bark cloth plies and the developed composites were also studied for their sound absorption properties.

\section{Experimental}

\subsection{Materials}

Bark cloth (Figure 1) was extracted from F. natalensis, Ficus brachypoda and Antiaris toxicaria using the method described by Rwawiire \& Tomkova [24]. Epoxy resin LG285 and hardener HG285 supplied by GRM systems, Czech Republic, was used in composite sample fabrication.

\subsection{Composite fabrication}

Epoxy resin LG285 and Hardener HG285 supplied by GRM systems, Czech Republic was used in composite sample fabrication. The resin to hardener ratio was maintained at 100:40 as per the manufacturer's directives; Vacuum Assisted Resin Transfer Molding (VARTM) was used to prepare the Bark Cloth Fibre Reinforced Composites (BFRC) (Figure 2). Four bark cloth plies were used in the manufacture of the composites, resin was infused into the fibre performs using vacuum pressure. The composite was left to cure at room temperature for 72 hours.

\subsection{Characterisation methods}

\section{Morphology}

The microstructures of the fabrics were investigated using a Vegas-Tescan scanning electron microscope (SEM) with accelerating voltage of $20 \mathrm{KV}$.

\section{Acoustic properties}

The acoustic properties of the bark cloth and its composite were investigated using a type 4206 Brüel \& Kjær impedance tube according to ISO10534-2 standard using two quarter-inch condenser microphones type 4187 (Figure 3).

The principle of measurement works in such a way that the sound source is generated by a loudspeaker at the end of the impedance tube; the sound waves are transmitted to the

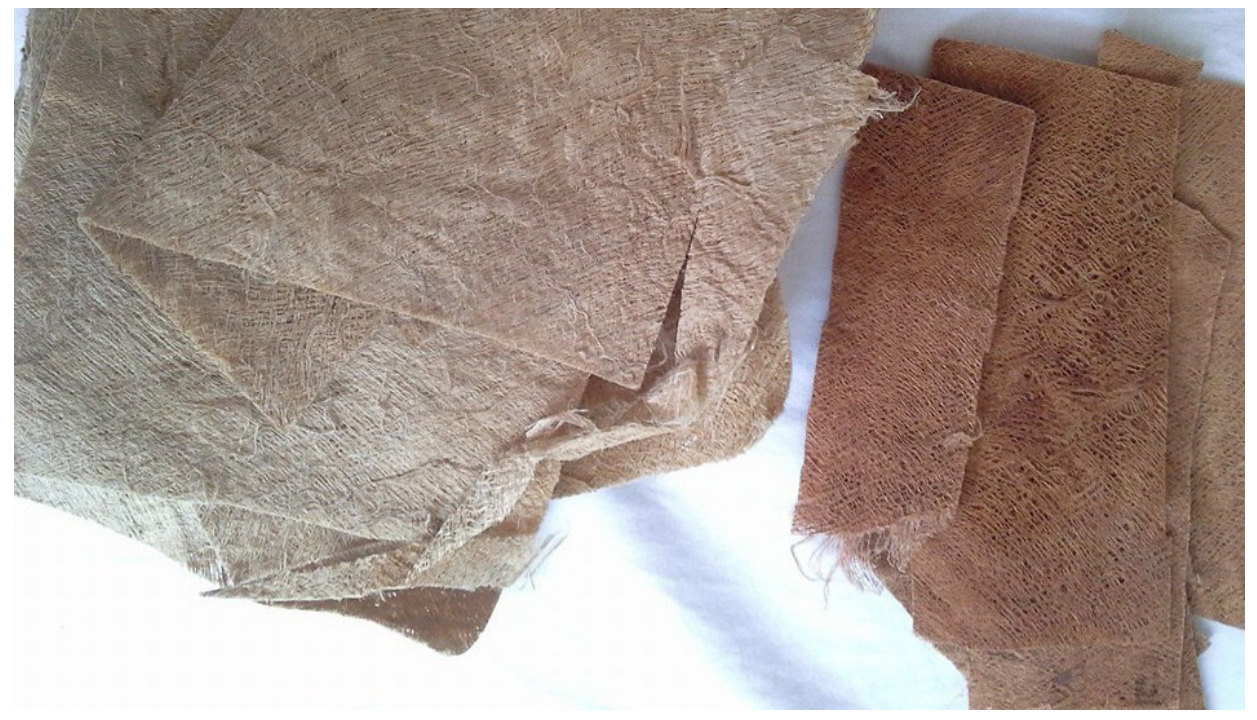

Figure 1: Bark cloth samples 
(A)
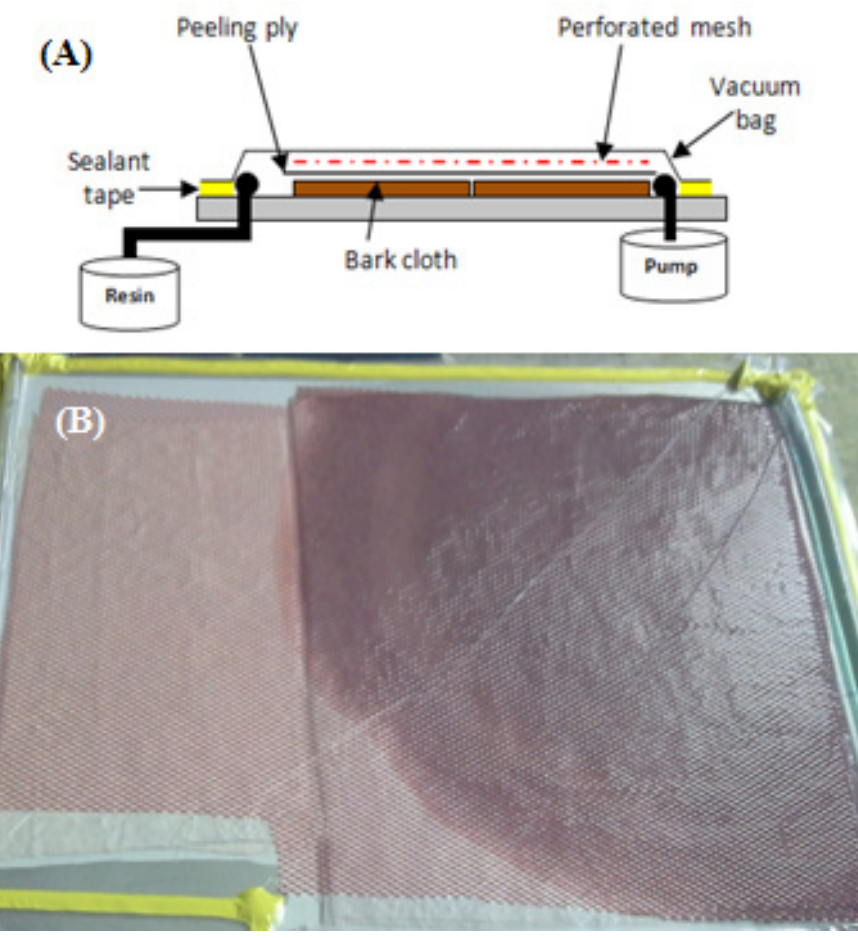

Figure 2. Bark cloth ply samples being infused with resin using VARTM

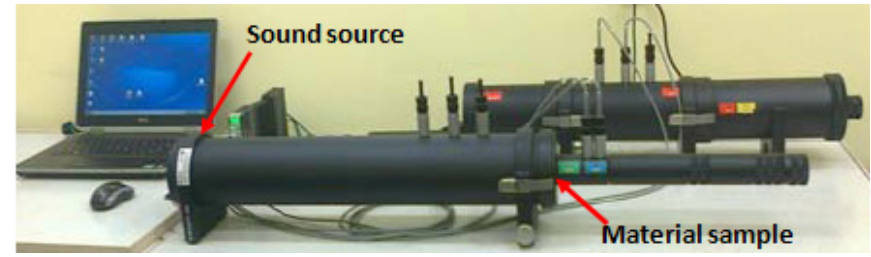

Figure 3: Brüel \& Kjær impedance tube

surface of the material sample (Figure 3). When a sound wave strikes the bark cloth materials, it would cause vibration of the particles causing friction, thereby generating heat, which is absorbed by the bark cloth and some sound energy is reflected and picked up by sensors.

Bark cloth being a non-woven material, its ability to absorb sound is influenced by the fibre network that dissipate the sound energy and also absorb the heat generated as the sound energy is being dissipated.

The tube measures the physical sound absorption coefficient (the fraction of acoustic energy not reflected by the material surface), which is a quotient of acoustic energy absorbed by the material to the energy of the incident wave.

The material samples had a diameter of $29 \mathrm{~mm}$ and were studied in the frequency range of $500-6400 \mathrm{~Hz}$.

The composite and multilayer samples were cut to the above diameter according to the standard. The sound absorption coefficient was measured for composites, single layer, double layers, triple layers and finally, quadruple layers. Since the fabricated BFRC specimens had four plies, acoustic characteristics had to be characterised for the respective bark cloth layers and their effects on sound absorption.
Table 1: Sample thickness.

\begin{tabular}{|c|c|c|}
\hline No. & Sample & Thickness [mm] \\
\hline 1 & A. toxicaria & \\
\cline { 2 - 3 } & First layer & 1.07 \\
\cline { 2 - 3 } & Second layer & 1.25 \\
\cline { 2 - 3 } & Third layer & 0.98 \\
\cline { 2 - 3 } & Fourth layer & 1.33 \\
\hline \multirow{4}{*}{2} & Total thickness & 4.63 \\
\cline { 2 - 3 } & Antiaris BFRC & 2.50 \\
\cline { 2 - 3 } & F. brachypoda & \\
\cline { 2 - 3 } & First layer & 1.33 \\
\cline { 2 - 3 } & Second layer & 1.12 \\
\cline { 2 - 3 } & Third layer & 1.23 \\
\cline { 2 - 3 } & Fourth layer & 1.38 \\
\hline \multirow{4}{*}{3} & Total thickness & 5.06 \\
\cline { 2 - 3 } & F. brachypoda BFRC & 2.12 \\
\cline { 2 - 3 } & F. natalensis & \\
\cline { 2 - 3 } & First layer & 1.02 \\
\cline { 2 - 3 } & Second layer & 1.42 \\
\cline { 2 - 3 } & Third layer & 0.72 \\
\hline & Fourth layer & 1.03 \\
\hline & Total thickness & 4.19 \\
\hline F. natalensis BFRC & 2.93 \\
\hline
\end{tabular}

Table 1 shows the thickness of the non-woven felts used.

\section{Results and discussion}

\section{Morphology}

The fabric fibre morphologies are shown in Figures 4 and 5 . It is observed that the bark cloth fabrics are composed of a network of fibres that are embedded with woody substances. Bark cloth obtained from Ficus species has more plant and woody material on the fibre structure. This material acts as a binder that binds the bark cloth microfibres together. The transverse section of the cloth shows that the microfibres are polygonal in shape, however, encased in the woody material (Figure 5). The air gaps that exist between the fibre enclosure and the woody material dictate the sound absorption properties of the fabrics.

The ability of a non-woven material to act as an efficient sound absorption material is influenced by the fibre network and the morphology of the respective fibres. It is observed that bark cloth is made up of various microfibres of diameter ranging from 20 to $30 \mu \mathrm{m}$ in diameter (Figure 5). It is these fibres that play a major role in absorbing the incident sound energy as well as absorbing the resulting heat from dissipation of sound energy. 

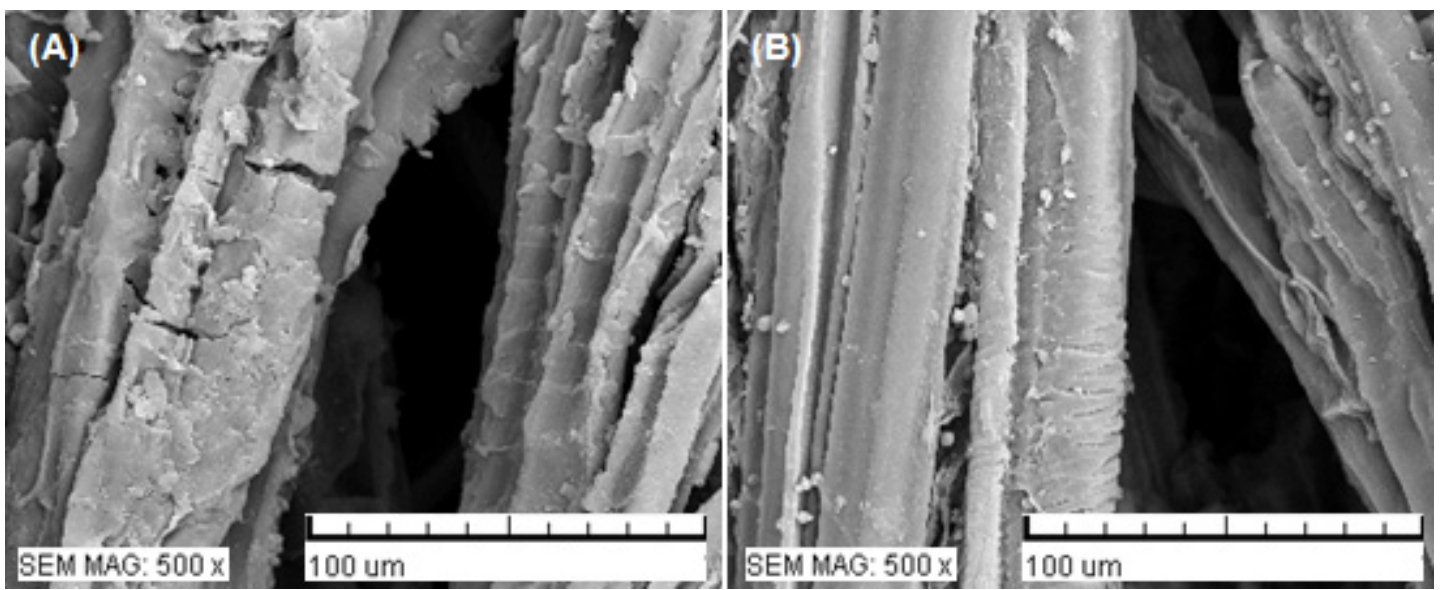

Figure 4: Fibre morphology of (A) F. natalensis (B) A. toxicaria
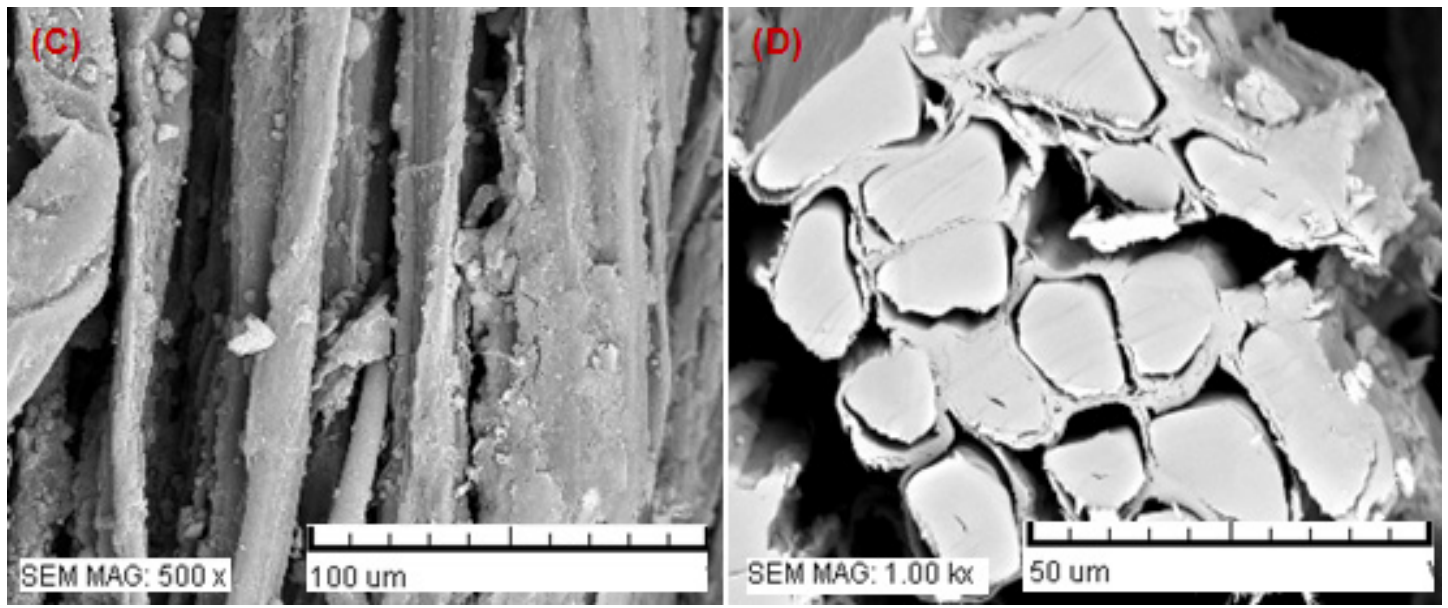

Figure 5: Fibre morphology of (C) Ficus brachypoda (D) Transverse sectional view

\section{Acoustic properties}

The acoustic properties of one-layer fabrics of the three species are shown in Figure 6. The sound absorption properties for one-layer samples of the bark cloth fabrics with the thickness of about 1.14 $\mathrm{mm}$ are similar for each kind of samples. The sound absorption coefficient generally increases with increase of frequency.

The one-layer bark cloth fabrics between the frequency range of $1000-3200 \mathrm{~Hz}$ have an average sound absorption coefficient of 0.05 , whereas beyond $5000 \mathrm{~Hz}$, the fabric's sound absorption is becomes 0.1 and the properties favourable to Antiaris and $F$. natalensis bark cloth.

The effect of layer thickness was investigated and Figure 7 shows the sound absorption properties of $F$. natalensis fabrics with one, two, three and four layers. The sound absorption properties increase with increase in sample thickness. All the fabrics studied had a gradual increase of sound absorption coefficient. F. natalensis' four-layer fabrics had a sound absorption coefficient of 0.7 at $6400 \mathrm{~Hz}$.

The two-layer samples showed a sound absorption coefficient of 0.1 at $3000 \mathrm{~Hz} ; 0.15$ at $4000 \mathrm{~Hz} ; 0.2$ at $5000 \mathrm{~Hz}$ and 0.25 at $6000 \mathrm{~Hz}$. The addition of another layer almost doubled the sound absorption performance of the fabrics as can be seen in the behaviour of the samples with three layers.
F. brachypoda fabrics showed similar behaviour as F. natalensis fabrics (Figure 8). It is observed that the three-layer fabrics of $F$. natalensis were better than for F. brachypoda as can be seen from the graphs. F. brachypoda had a sound-absortion coefficient of 0.71 at $6400 \mathrm{~Hz}$.

The sound absorption performance of $A$. toxicaria fabrics is presented in Figure 9. It is observed that the performance of the fabrics at $6400 \mathrm{~Hz}$ was overall best having a sound absorption coefficient of 0.92 compared to the average of 0.7 obtained from the Ficus bark cloth species. Krucinska et al. [27] showed that cotton/PLA composites of $5.8 \mathrm{~mm}$ thickness with microfibres had a sound absorption coefficient of 0.93 at 6400 $\mathrm{Hz}$. The bark cloth fabrics showed an irregular dependence of sound absorption coefficient of like other non-wovens over a wide range of frequency, this behaviour was also confirmed elsewhere [26].

The comparable excellent acoustic properties of bark cloth fabrics at high frequencies are attributed to fibre entanglement in the fabrics and porosity. Antiaris bark cloth with four layers showed better sound absorption properties compared to other types of bark cloth. The investigated sound absorption properties showed that $A$. toxicaria bark cloth has higher sound absorption properties at higher frequencies. Increasing the bark cloth, fibre layers showed a positive trend towards sound absorption coefficient; thus, giving a prediction of multilayer 


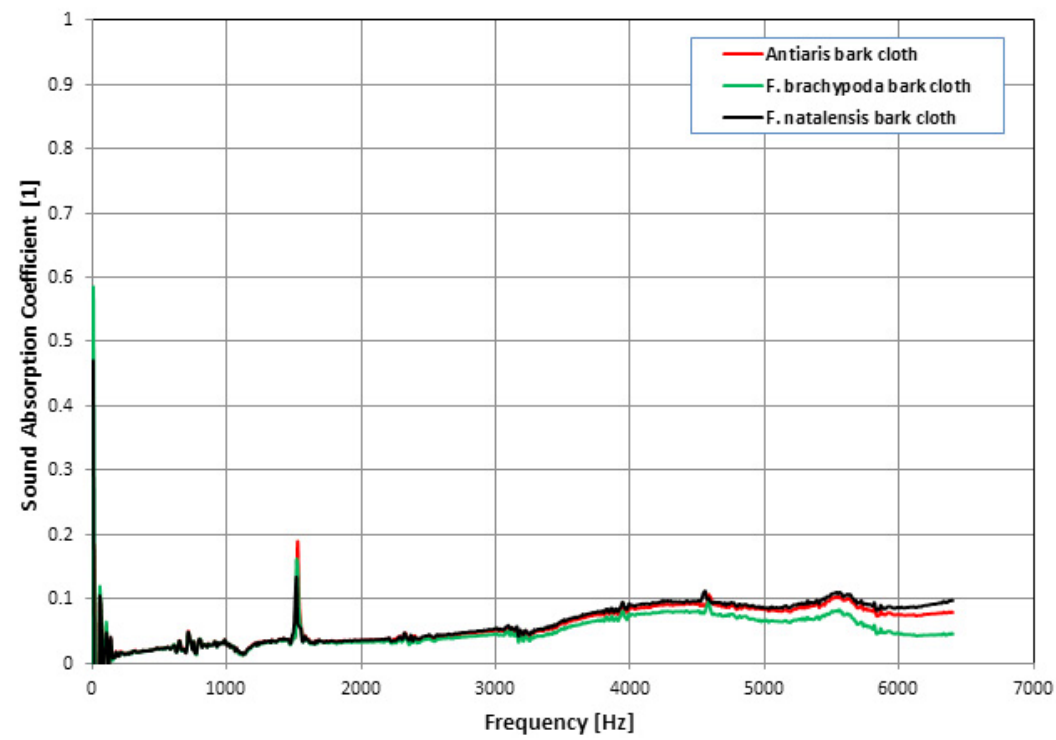

Figure 6: One-layer bark cloth sound absorption properties.

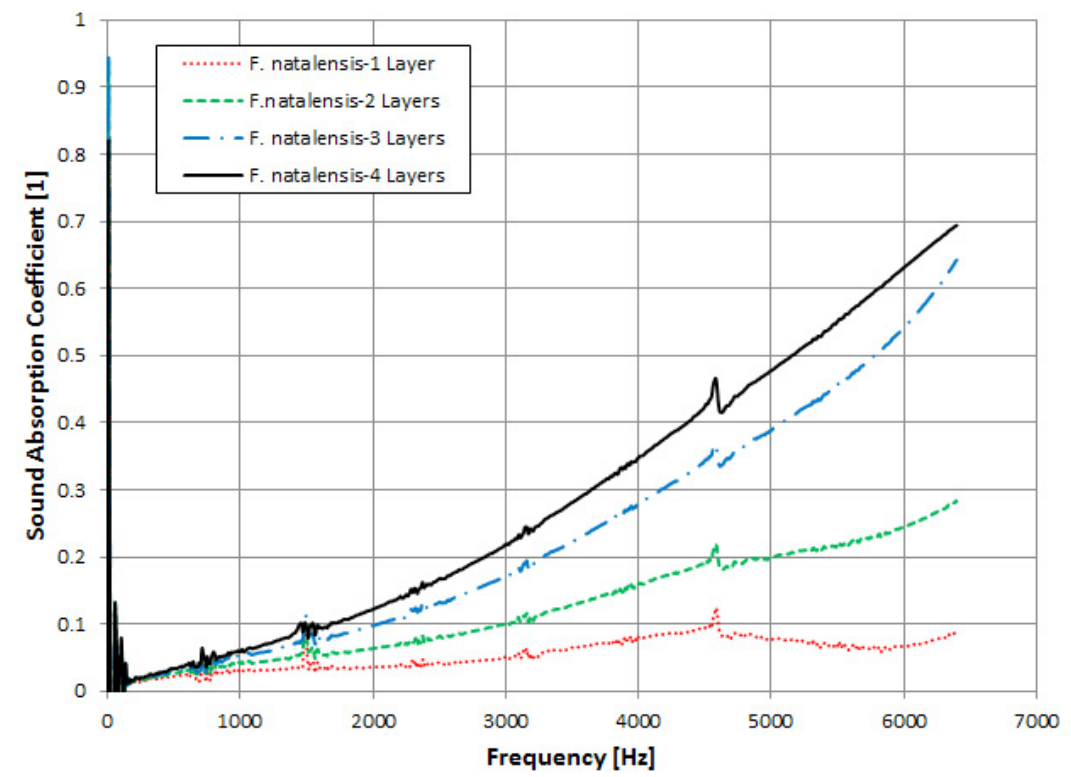

Figure 7: F. natalensis bark cloth sound absorption properties

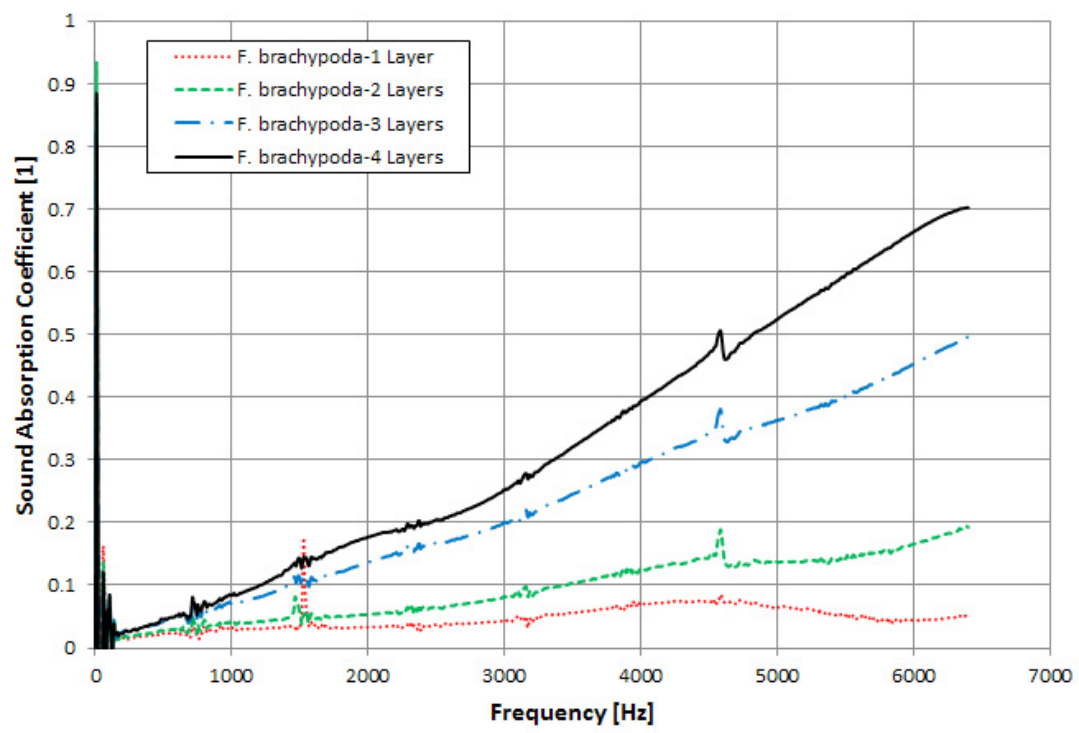

Figure 8: F. brachypoda bark cloth sound absorption properties 


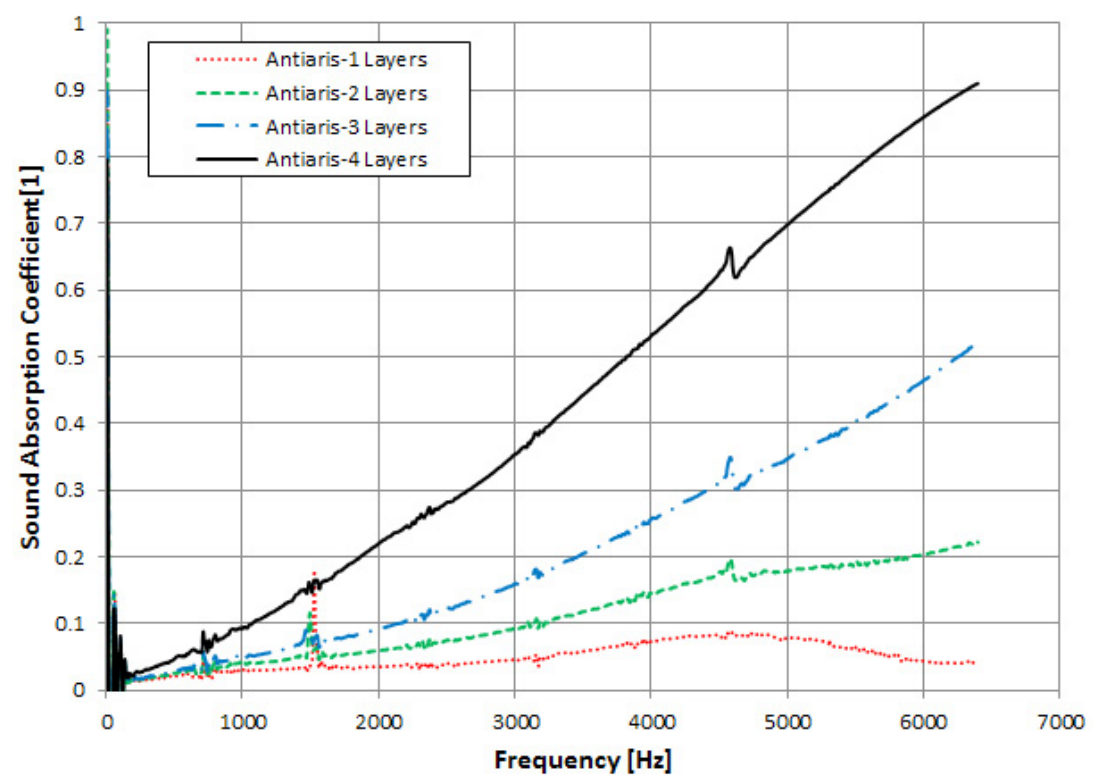

Figure 9: Antiaris toxicaria bark cloth sound absorption properties

products of Antiaris bark cloth the potential to provide positive results even at low-frequency ranges.

The increase of the bark cloth layers increases the contact surface area for the incident sound waves; this, therefore, increases more absorption of heat due to the heat dissipation and also leads to less reflection of the waves.

Jiang et al. [25] showed that the base layer of cotton with thickness of $35 \mathrm{~mm}$ had a sound absorption coefficient of approximately 0.92 , whereas the composite of the cotton base layer and glass layer of $3 \mathrm{~mm}$ having a total thickness of $38 \mathrm{~mm}$ had a sound absorption coefficient of 0.95 . In comparison to the four-layer bark cloth, non-woven fabrics that had the highest thickness of $5.06 \mathrm{~mm}$, bark cloth performance was exceptional since Antiaris bark cloth with thickness of $4.06 \mathrm{~mm}$ had a sound absorption coefficient of 0.91 at $6400 \mathrm{~Hz}$.

The sound absorption properties were investigated further whereby the four layers of bark cloth were utilised in the production of composites. Two surfaces were investigated in order to understand whether the perturbations on the composite surface have an effect on the sound absorption properties. The molded composites' sound absorption properties of smooth surfaces are shown in Figure 10.

The Ficus bark cloth composites have a sound absorption coefficient below 0.1 for the frequency of up to $3700 \mathrm{~Hz}$ and thereafter, F. brachypoda sound absorption properties increased with increase in frequency reaching its peak of 0.35 at $6400 \mathrm{~Hz}$. Antiaris BFRC sound absorption, increased for frequency of $5000 \mathrm{~Hz}$ and then decreased, showing the same trend with F. natalensis BFRC.

The effect of surface perturbations on the sound absorption properties is shown in Figure 11, which showed a marked increase in the sound absorption properties. It is observed that the perturbations increased the sound absorption properties of Antiaris BFRC having an average sound absorption coefficient of 0.15 between frequency ranges of $2500-5000$ $\mathrm{Hz}$.

The low performance of the composites with sound absorption is due to the effective packing of the method used for production of the composites. VARTM is an efficient method of production of composites with less voids and with smooth, even packing that showed insignificant sound absorption properties compared to the fabrics that were used to reinforce the epoxy resin. This is due to the fact when a sound wave strikes a porous fibre network like bark cloth; the sound waves cause vibration in the fibre network. The vibration causes minute heat build-up in the fibres due to friction. Therefore, a good absorbing material absorbs the energy of the sound waves and less heat is generated. However, in composites, the compaction of the bark cloth non-woven felt results in reduced porosity, thus increasing flow resistivity and reduced vibration of the fibre network, therefore a reduced sound absorption coefficient [28].

\section{CONCLUSION}

In this investigation, for the first time, bark cloth has been introduced as a potential sound absorption material.

The results show that bark cloth non-woven fabric has good sound absorption properties and can be used as an alternative replacement for the synthetic commercial fibres, which are widely used in the industry.

The investigated sound absorption properties showed that $A$. toxicaria bark cloth has higher sound absorption properties at higher frequencies. Increasing the bark cloth fibre layers showed a positive trend towards sound absorption coefficient, thus giving a prediction of multilayer products of Antiaris bark cloth the potential to provide positive results even at low frequency ranges. 


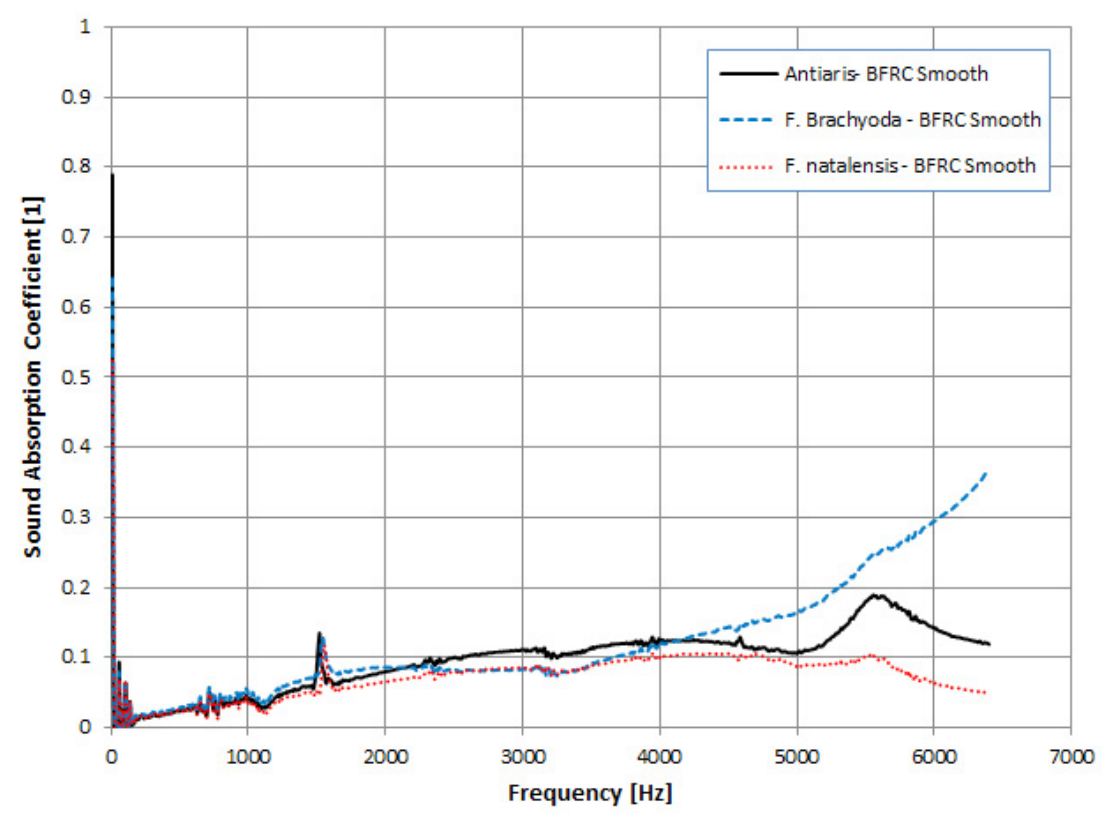

Figure 10: Bark cloth epoxy laminar composite sound absorption properties with smooth surfaces

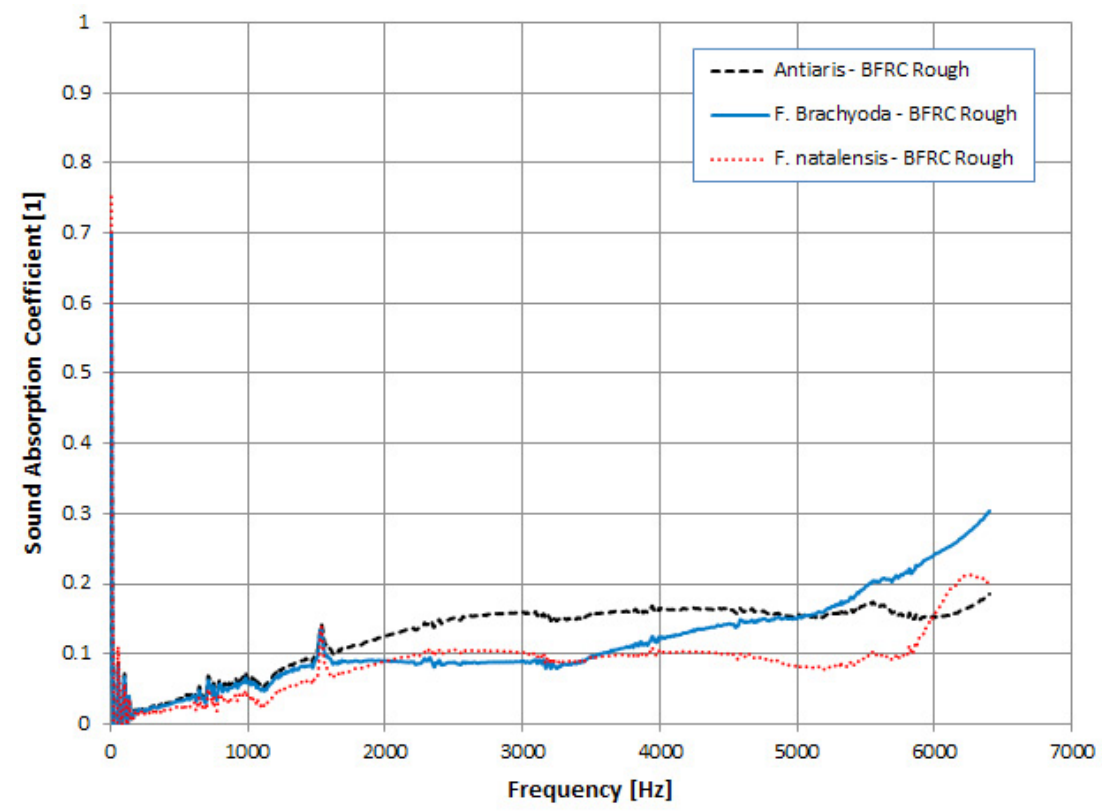

Figure 11: Bark cloth epoxy laminar composite sound absorption properties with surface perturbations

Production of composites showed that there is a decrease in the sound absorption properties due to the decrease in the porosity and thickness due to the compression of the fabrics under pressure, therefore reducing the vibration of the fibres since they are bonded in the matrix that increases stiffness and thereafter decreasing the overall acoustic properties of the bark cloth reinforced composites.

\section{ACKNOWLEDGEMENTS}

The first author is grateful to God for life given to carry out the research work. He is also grateful to Association of African Universities for "Small Dissertation Grant" through Busitema University and Technical University of Liberec for the doctoral study scholarship.

\section{References}

[1] Moszynski, P. (2011). WHO warns noise pollution is a growing hazard to health in Europe. BMJ, 342.

[2] Rwawiire, S., Luggya, G. W., Tomkova, B. (2013). Morphology, Thermal, and Mechanical Characterization of Bark Cloth from Ficus natalensis. ISRN Textiles, 2013.

[3] Koronis, G., Silva, A., \& Fontul, M. (2013). Green composites: a review of adequate materials for automotive applications. Composites. Part B, Engineering, 44(1), 120-127.

[4] Dittenber, D. B., \& GangaRao, H. V. (2012). Critical review of recent publications on use of natural composites in infrastructure. Composites Part A: Applied Science and Manufacturing, 43(8), 1419-1429.

[5] Mwasha, A. (2009). Designing bio-based geotextiles for reinforcing an embankment erected on the soft soil. 
Materials \& Design, 30(7), 2657-2664.

[6] Summerscales, J., Dissanayake, N. P., Virk, A. S., \& Hall, $W$. (2010). A review of bast fibres and their composites. Part 1-Fibres as reinforcements. Composites Part A: Applied Science and Manufacturing, 41(10), 1329-1335.

[7] Sapuan, S. M., \& Maleque, M. A. (2005). Design and fabrication of natural woven fabric reinforced epoxy composite for household telephone stand. Materials \& design, 26(1), 65-71.

[8] La Mantia, F. P., \& Morreale, M. (2011). Green composites: A brief review. Composites Part A: Applied Science and Manufacturing, 42(6), 579-588.

[9] http://www.researchandmarkets.com/reports/2881528/ global-natural-fiber-composites-market-2014-2019

[10] Faruk, O., Bledzki, A. K., Fink, H. P., Sain, M. (2014) Progress Report on Natural Fiber Reinforced Composites. Macromolecular Materials and Engineering, 299(1), 9-26.

[11] Hobson, J., Carus, M. (2011). Targets for bio-based composites and natural fibres. JEC composites, (63), 3132.

[12] Liu, D. T., Xia, K. F., Yang, R. D., Li, J., Chen, K. F., Nazhad, M. M. (2012). Manufacturing of a biocomposite with both thermal and acoustic properties. Journal of Composite Materials, 46(9), 1011-1020

[13] Fatima, S., Mohanty, A. R. (2011). Acoustical and fireretardant properties of jute composite materials. Applied Acoustics, 72(2), 108-114.

[14] Zulkifh, R., Nor, M. M., Tahir, M. M., Ismail, A. R., Nuawi, M. Z. (2008). Acoustic properties of multi-layer coir fibres sound absorption panel. Journal of Applied Sciences, 8(20), 3709-3714.

[15] Yang, H. S., Kim, D. J., \& Kim, H. J. (2003). Rice strawwood particle composite for sound absorbing wooden construction materials. Bioresource Technology, 86(2), 117-121.

[16] Gliścińska, E., Michalak, M., Krucińska, I., Kazimierczak, J., Bloda, A., \& Ciechańska, D. (2013). Sound Absorbing Composites from Nonwoven and Cellulose Submicrofibres. Journal of Chemistry and Chemical Engineering, 7, 942948.

[17] Hosseini Fouladi, M., Ayub, M., \& Jailani Mohd Nor, M. (2011). Analysis of coir fiber acoustical characteristics. Applied Acoustics, 72(1), 35-42.
[18] Khedari, J., Nankongnab, N., Hirunlabh, J., Teekasap, S. (2004). New low-cost insulation particleboards from mixture of durian peel and coconut coir. Building and environment, 39(1), 59-65.

[19] Mahzan, S., M Ahmad Zaidi, A., Arsat, N., NM Hatta, M., I Ghazali, M., RasoolMohideen, S. (2010). Study on sound absorption properties of coconut coir fibre reinforced composite with added recycled rubber. International Journal of Integrated Engineering, 2(1), 29-34.

[20] Doost-hoseini, K., Taghiyari, H. R., Elyasi, A. (2014). Correlation between sound absorption coefficients with physical and mechanical properties of insulation boards made from sugar cane bagasse. Composites Part B: Engineering, 58, 10-15.

[21] Ersoy, S., Küçük, H. (2009). Investigation of industrial tealeaf-fibre waste material for its sound absorption properties. Applied Acoustics, 70(1), 215-220.

[22] Yang, H. S., Kim, D. J., Kim, H. J. (2003). Rice strawwood particle composite for sound absorbing wooden construction materials. Bioresource Technology, 86(2), 117-121.

[23] Xiang, H. F., Wang, D., Liua, H. C. (2013). Investigation on sound absorption properties of kapok fibers. Chinese Journal of Polymer Science, 31(3), 521-529.

[24] Rwawiire, S., Tomkova, B. (2014). Thermo-physiological and comfort properties of Ugandan barkcloth from Ficus natalensis. The Journal of The Textile Institute, 105(6), 648-653.

[25] Jiang, N., Chen, J. Y., \& Parikh, D. V. (2009). Acoustical evaluation of carbonized and activated cotton nonwovens. Bioresource technology, 100(24), 6533-6536.

[26] Gliścińska, E., Michalak, M., Krucińska, I. Sound absorption property of nonwoven based composites. Autex Research Journal, 13(4), 150-155.

[27] Krucińska, I., Gliścińska, E., Michalak, M., Ciechańska, D., Kazimierczak, J., Bloda, A. (2014). Soundabsorbing green composites based on cellulose ultrashort/ultra-fine fibers. Textile Research Journal, DOI: 10.1177/0040517514553873

[28] Maderuelo-Sanz, R., Nadal-Gisbert, A. V., Crespo-Amorós, J. E., Parres-García, F. (2012). A novel sound absorber with recycled fibers coming from end of life tires (ELTS). Applied Acoustics, 73(4), 402-408. 